\title{
Introdução de Disciplinas na Modalidade EAD para Cursos de Qualificação Profissional: Propostas para um Ambiente
} Favorável

\author{
Dagmar Dias Cerqueira1, Jessica Sarubi de Moura*2
}

\begin{abstract}
1 Mestranda em Educação, Comunicação e Cultura nas Periferias Urbanas, Faculdade de Educação da Baixada Fluminense / Universidade do Estado do Rio de Janeiro/UERJ. Rua General Manoel Rabelo, s/n Vila São Luís, Duque de Caxias - RJ - Brasil. dagdc@oi.com.br

2 Mestre em Educação, Comunicação e Cultura nas Periferias Urbanas, Faculdade de Educação da Baixada Fluminense / Universidade do Estado do Rio de Janeiro/UERJ. Rua General Manoel Rabelo, s/n - Vila São Luís, Duque de Caxias - RJ - Brasil. jessicasarubi@yahoo.com.br
\end{abstract}

\section{Resumo}

A pesquisa em foco busca analisar a inserção de disciplinas, na modalidade EAD, para Cursos de Qualificação Profissional em um Centro Vocacional Tecnológico de Construção Civil do Estado do Rio de Janeiro. A investigação pretende verificar se os ambientes educativos são favoráveis à implantação de Educação a Distância - EAD, bem como propor condições favoráveis para um Ambiente Virtual de Aprendizagem $(A \vee A)$. O presente trabalho tem seu enfoque também na cibercultura e nas mutações contemporâneas da relação com o saber (Lévy 1999) e se utiliza de Spritzer e Bittencourt (2009) para abordar questões referentes à qualidade pedagógica e técnica dos cursos mediatizados pela EAD. A metodologia da pesquisa com abordagem qualitativa se utiliza dos seguintes procedimentos metodológicos: observação participante, entrevista semipadronizada e pesquisa documental. Ao final da pesquisa de campo e do levantamento bibliográfico, são feitas pontuações sobre possíveis ambientes favoráveis que permitam viabilizar a modalidade EAD nos cursos de qualificação no Centro Vocacional Tecnológico, como também, tornam possível diagnosticar que, por vezes, a EAD se configura como mecanismo que promove distanciamento entre sujeito e informação.

Palavras-chave: Educação a distância; Qualificação profissional; Inclusão social. 


\title{
Introduction Courses to EAD Professional Qualification: Proposals for a Friendly Environment
}

\begin{abstract}
Abstract

The focus of the reasearch is to analyze the inclusion of disciplines in DL mode for Professional Training Courses, in a Vocational Technology Center of Civil State of Rio de Janeiro Construction. The research aims to assess whether educational environments are conducive to the implementation of Distance Education - Distance Education and to propose favorable conditions for a Virtual Learning Environment (VLE). This work focuses on cyberculture and also on contemporary mutations of relationship to knowledge (Lévy 1999). It uses Spritzer and Bittencourt (2009) to address issues of pedagogical and technical quality of courses mediated by EAD. The research methodology with a qualitative approach uses the following instruments: participant observation, semipadronizada interview, and documentary research. At the end of the field research and literature, scores are made about possible favorable environments that enable distance education modality in training courses in the Vocational Technology Center. These scores also make it possible to diagnose that sometimes, EAD is configured as a mechanism promoting detachment between subject and information.
\end{abstract}

Keywords: Distance education; Vocational qualification; Social inclusion. 


\section{Introdução}

O interesse pela temática da pesquisa veio de uma inquietação que surgiu no próprio ambiente de trabalho a partir das vivências postas pelo cotidiano.

A partir de 2012, os CVTs (Centros Vocacionais Tecnológicos) introduziram, em seus cursos de Qualificação Profissional, aulas em EAD para as disciplinas de Matemática, Português e Ética. Cabe ressaltar que a exigência para frequentar esses cursos é a de que o aluno tenha concluído o sexto ano do ensino fundamental.

Desde 2011, foi estabelecido contato com o espaço que se configurou objeto de pesquisa: um CVT do Rio de Janeiro que disponibiliza Cursos de Qualificação Profissional em Construção Civil. Com as mudanças ocorridas, em 2012, surgiu uma inquietação ao ver que as aulas das disciplinas de Português, Matemática e Ética, que eram disponibilizadas na modalidade presencial, passariam a ser disponibilizadas na modalidade EAD. O discurso para essa modificação era o de promover a inclusão digital dos alunos. Surgiu, então, o questionamento por saber qual seria a receptividade que esses alunos trariam, já que tinham escolaridade de apenas até o sexto ano do ensino fundamental e estavam ali com o objetivo de serem qualificados profissionalmente para se tornarem pedreiros, ladrilheiros e outras profissões afins.

O trabalho apresentado propõe analisar a inserção de aulas, na modalidade EAD, para cursos de Qualificação Profissional. Será usado um CVT de Construção Civil como campo de estudo, no qual foram inseridas aulas na modalidade EAD, especificamente, nas disciplinas de Português, Matemática e Ética.

A investigação visa buscar respostas às seguintes questões:

- A inserção da EAD nesse cenário vem tornar esse modelo educativo mais inclusivo?

- Todos os ambientes educativos são favoráveis à inserção de EAD?

- Quais as propostas de um ambiente educativo favorável à implantação de Ambientes Virtuais de Aprendizagem?

Trata-se de um Estudo de caso instrumental (Stake, 2000, apud, Mazzoti, 2006, p.641), tendo como recorte um CVT de Construção Civil da Rede FAETEC.

No estudo de caso instrumental, ao contrário, o interesse no caso deve-se à crença de que ele poderá facilitar a compreensão de algo mais amplo, uma vez que pode servir para fornecer insights sobre um assunto ou para contestar uma generalização amplamente aceita, apresentando um caso que nela não se encaixa. (STAKE, 2000, apud, MAZZOTI, 2006, p.641) 
Mazzotti (2006) expõe sobre a complexidade do estudo de caso, visto que requer técnicas variadas de coleta de dados, e que nem todo estudo de uma única unidade pode ser considerado um estudo de caso. Há que se buscar sua singularidade. Nesse caso considera-se que a singularidade está na aplicação da EAD para cursos de qualificação, pois, até então, a EAD era aplicada especificamente em cursos de nível técnico, graduação, extensão ou pós-graduação.

A autora afirma que a proposta de "generalização naturalística", detalhada por Stake, é uma mudança de perspectiva:

Sugere que ao invés de assumir a responsabilidade de definir para que populações e/ou contextos os resultados obtidos podem ser generalizados, o pesquisador deixe essa decisão para o leitor. Este, ao se deparar com a descrição detalhada dos sujeitos, das relações que mantêm entre si, de seus comportamentos e das situações em que ocorrem, enfim, com uma "descrição densa" do caso, decidirá se as interpretações, hipóteses, insights apresentados naquele estudo podem ser aplicados ao caso de seu interesse. (MAZZOTTI, 2006, p. 650)

O referencial teórico para a pesquisa se distribui em relação a alguns conceitos relativos à educação profissional estabelecidos pelas políticas públicas (Brasil, MEC, 2007) e relações entre a educação tecnocientífica e cidadania (Martín- Gordillo, 2003). O trabalho abordará também sobre a cibercultura e as mutações contemporâneas da relação com o saber (Lévy, 1999 e 1998), Spritzer e Bittencourt (2009) e Belloni (2006), que afirmam tratar sobre a qualidade pedagógica e técnica dos cursos mediatizados de EAD.

Para que não se perca o foco das pontuações da pesquisa, foram elaborados os objetivos, que se apresentam divididos em: objetivo geral e objetivos específicos.

- Objetivo geral:

Analisar a inserção de EAD em cursos de Qualificação Profissional quanto à inclusão social.

- Objetivos específicos:

$\checkmark$ Relacionar as NTICs (Novas Tecnologias de Informação e Comunicação) com novos espaços para promoção do saber. 
Identificar as considerações para implantação de EAD em cursos de Qualificação Profissional.

Descrever o processo educativo realizado nos Cursos de Qualificação Profissional.

\section{Metodologia}

Quanto aos procedimentos metodológicos, o estudo de caso, com abordagem qualitativa, se utiliza de métodos diferenciados como: observação participante da atuação da equipe técnico-pedagógica, análise documental feita através de gráficos e levantamentos elaborados pela Unidade de Ensino, por quatro meses, e entrevista semipadronizada de quatros alunos egressos dos Cursos de Qualificação Profissional e dois componentes da equipe técnico-pedagógica. Esses procedimentos são embasados por Flick (2009); Figueiredo (2011); e Castro, (2013).

Apesar de utilizar gráficos para apreciação, este estudo será predominantemente qualitativo.

\section{Resultados e discussão}

Foram disponibilizadas para a pesquisa algumas tabelas e gráficos informando o número de matriculados e o número de alunos concluintes nos cursos de Qualificação Profissional a partir do ano de 2011, bem como o Catálogo FAETEC, Fundação de Apoio à Escola Técnica do Estado do Rio de Janeiro, 2013.

\begin{tabular}{|l|c|c|c|c|c|c|c|c|}
\hline \multirow{3}{*}{ cursos } & \multicolumn{9}{|c|}{ PERÍODOS/MATRICULADOS/CONCLUINTES } \\
\cline { 2 - 10 } & \multicolumn{2}{|c|}{$\mathbf{2 0 1 1 / 2}$} & \multicolumn{2}{c|}{$\mathbf{2 0 1 1 / 3}$} & \multicolumn{2}{c|}{$\mathbf{2 0 1 2 / 1}$} & \multicolumn{2}{c|}{$\mathbf{2 0 1 2 / 2}$} \\
\cline { 2 - 10 } & Mat. & Concl. & Mat. & Concl. & Mat. & Concl. & Mat. & Concl. \\
\hline Armador & 40 & 23 & 9 & 3 & & & 29 & 14 \\
\hline Almoxarife de Obras & 59 & 33 & & & 31 & 13 & 25 & 7 \\
\hline Instalador Bombeiro & 89 & 46 & 20 & 6 & 28 & 14 & 54 & 28 \\
\hline Carpinteiro & 62 & 30 & & & 9 & 1 & 13 & 4 \\
\hline Eletricista Predial & 113 & 79 & 48 & 30 & 86 & 47 & 102 & 65 \\
\hline Aplicador de Revestimento & 80 & 50 & 19 & 13 & 35 & 12 & 45 & 21 \\
\hline Pedreiro & 26 & 15 & 25 & 9 & 57 & 31 & 68 & 35 \\
\hline
\end{tabular}

Obs.: No período 2011/3 não foram oferecidas vagas para os cursos de Almoxarife de Obras e Carpinteiro. Em 2012/1 não foram oferecidas vagas para o curso de Armador.

Quadro 1: Relação entre matriculados e concluintes no período compreendido entre 2011 a 2012. 
Observando o quadro, que deu origem a outros gráficos, elaborados pela própria instituição, é possível perceber que a partir da data (2011/3), em que foram instituídas as inscrições on-line para os interessados em se matricular, nos respectivos cursos, houve uma queda significativa do número de matriculados, no primeiro momento, mas apesar de uma ampliação, o quantitativo de matriculados ainda permaneceu reduzido, com exceção dos cursos para pedreiros. Essa redução foi acompanhada pelo total de concluintes também. Além disso, pode ser percebido que o impacto gerado pela inserção do processo de inscrições on-line foi minimizando nos anos posteriores.

O mesmo fato pode ser observado com relação à implantação das aulas on-line de matemática, português, e ética, a partir do ano de 2012, onde pode ser percebido pelo mesmo gráfico, que apenas cerca da metade dos alunos matriculados conseguiam concluir os cursos.

A instituição, logo que percebeu essa redução nos quantitativos e na medida em que ocorreram, tomou providências para que o problema fosse minimizado.

Com relação à diminuição de inscritos on-line, foram realizadas chamadas posteriores dos interessados para matrículas de vagas ociosas que foram realizadas diretamente na instituição. Para melhorar o índice de concluintes, foram estipuladas aulas presenciais com os professores de matemática e português tendo a finalidade de ajudar os alunos na navegação pela plataforma on-line.

Para dar continuidade à pesquisa e captar maiores subsídios para a pesquisa, optou-se pelo modelo de entrevista semipadronizada com perguntas elaboradas de forma a dar clareza para os entrevistados e em pequena quantidade para que os entrevistados não se sentissem ansiosos pelo término das mesmas. Houve preocupação com um ambiente silencioso e agradável para que as entrevistas não fossem interrompidas.

Foram entrevistados uma orientadora educacional, uma professora da disciplina de Português dos cursos e quatro alunos. Foram realizadas quatro perguntas, para todos os entrevistados, que buscavam analisar o impacto causado pela introdução das aulas na modalidade EAD nos cursos de qualificação. Os alunos selecionados foram os que já haviam frequentado vários cursos na Instituição. À medida que as perguntas eram respondidas, havia momentos de intervenção de novas perguntas, para um melhor entendimento e clareza da opinião de cada entrevistado. As perguntas foram elaboradas traçando-se um paralelo entre os objetivos da pesquisa e as perguntas a serem realizadas. 
Ao serem questionados sobre as aulas realizadas pela plataforma on-line, houve concordância entre a orientadora educacional e a maioria dos alunos entrevistados quanto à dificuldade em usar os equipamentos, a dificuldade na relação professor/aluno para aquisição do saber e a ocorrência de assuntos abordados que não estariam em consonância com as avaliações e com a programação dos cursos.

Esse consenso na dificuldade na relação professor/aluno nas aulas on-line se relaciona com a fala de Belloni (2006) quando menciona que saber "mediatizar" será umas das competências mais importantes e indispensáveis à concepção e realização de qualquer ação EAD.

Nesse sentido, pelos comentários das entrevistas, fica marcante o valor da mediatização criada pela instituição, não de forma on-line, mas da maneira presencial auxiliando os alunos com dificuldades, na própria unidade, e que vai ao encontro dos caminhos possíveis para a operacionalização de um processo educativo efetivamente centrado no estudante, direcionando-o à autonomia concebida para a EAD por Belloni (2006):

Ênfase na interação social entre estudantes, professores e instituição, com o uso das técnicas de comunicação mais adequadas, criação de estruturas de apoio pedagógico e didático ao estudante (tutoria, aconselhamento, plantão de respostas a dúvidas, monitoria para o uso de tecnologias etc. Belloni (2006, p. 249)

Pelas falas dos entrevistados, também é possível perceber algumas formas negativas advindas pela cibercultura afirmadas por Belloni (2006) como isolamento e dominação, já que parte dos entrevistados afirma que perceberam abandono de colegas devido às dificuldades na utilização de artefatos tecnológicos:

"Ah, piores, porque a aula presencial, quando você tem dúvida o professor tem várias técnicas para passar aquilo que você tem dúvida, e na plataforma, você só tem um direcionamento, aquele que está lá. Presencial é dif..., presencial é... como é que é... plataforma é bom pra quem já sabe, pra quem não sabe... porque aqui é o caso... as pessoas vêm aqui fazer o curso, pararam de estudar há muito tempo. Mas não tem jeito, elas têm que ter um apoio presencial pra poder aprender pra poder ter um apoio pra fazer aquela prova." (Entrevistado B)

"Pra mim eu acho que... regular... sinceramente, eu não sou muito a favor de fazer aula on-line, não... eu sou mais com o professor, ali na frente do quadro... Posso não saber acessar... entendeu... o site... e... não gosto muito de fazer... não. Aulas... on-line. Tem muita gente 
também que não consegue acessar o site direito e tem muita gente também que não tem computador e a pessoa acaba desistindo do curso." (Entrevistado D)

A fala da orientadora educacional comprova essa tendência ao isolamento mostrada pelos alunos, e à tentativa da Unidade de Ensino em mediatizar, através de outros meios:

\begin{abstract}
"Ih, assustaram! Olha tivemos muitos alunos, assim... que não queriam fazer, alguns desistiram... Nós tivemos que fazer um trabalho com eles. A unidade disponibilizou equipamentos aqui mesmo na unidade com professores, para eles pudessem se familiarizar com o equipamento, mas, assim, eles ficaram assustados mesmo. Eu acho que... pra muitos, como eu disse antes não foi muito proveitoso, não. Porque o aluno gosta mesmo é de estar... do lado do professor tirando as dúvidas, questionando né... e, isto, assim..., afugentou um pouco os alunos." (Entrevistado A)
\end{abstract}

Com relação à aquisição do saber e a ocorrência de assuntos abordados que não estariam em consonância com as avaliações e com a programação dos cursos faz-se necessário lembrar que Lévy (1999) aponta que devemos construir novos modelos de espaço dos conhecimentos e que tenham convergência para "saberes superiores":

A partir de agora devemos preferir a imagem de espaços de conhecimentos emergentes, abertos, contínuos, em fluxo, não lineares, se reorganizando de acordo com os objetivos ou os contextos, nos quais cada um ocupa ma posição singular e evolutiva. (Lévy, 1999, p. 233)

Sendo assim seria necessário revisar e reavaliar as propostas dos cursos e todo o seu design instrucional para permitir melhor contextualização, correlação com os objetivos permitindo esta evolução do saber-fluxo.

Não se pode deixar de mencionar algumas pontuações de alunos que se mostraram orgulhosos em poder cursar disciplinas on-line:

"Eu acho legal esta forma de estudar. Você não precisa ficar preso aqui na Unidade, né... mas eu gostei mesmo porque o português estava bem puxado, a matemática mesmo, que parece ser tão fácil." (Entrevistado C)

Ocorreu também a busca de conhecimentos para o uso do computador entre os próprios familiares: 
"A única dificuldade que eu tive foi na parte do português. No computador eu tive uma dificuldade pouca... minha sobrinha me deu o incentivo de como teclar... eu não sou muito chegado à internet, mas aprendi e fui respondendo". (Entrevistado E)

"Achei legal assim... A matemática que há muito tempo eu não fazia aquelas coisas assim de porcentagem e cálculo e tinha umas ali que eu nem conseguia... aí, eu pedi ao meu marido... porque ele é bom em matemática. E tive algumas que eu até tive dificuldades... aquelas de porcentagem... de cúbicos... coisas de que eu não me lembrava mesmo." (Entrevistado C)

Outros mencionaram a possibilidade de criação de meios para driblar as avaliações on-line:

\footnotetext{
"Eu acho isto legal, né... Mas o que eu acho estranho é que tem formas de enrolar pra você saber a resposta... porque sem querer eu lá apertei um negócio e estava dando todas as questões, só que eu não conseguia voltar... E você estudante é meio malandro, você pode pegar a questão, né... E eu acho que tinha que bloquear, tipo, assim, você sabe a certa é a "a" e a "b", então você vai pegar no sistema pra refazer... eu acho que tivesse uma forma melhor de fazer o aluno estudar e não de ficar repetitivo... Mas eu gostei, achei bem interessante, mas acho que tem que ser melhor explorado porque, como eu falei, as questões... você pode até ver. Aquelas chances de fazer em até quatro vezes... é errado, porque o aluno fica assim... ah, não vou estudar, vou lá vou fazer... tinha que fazer a gente pensar mais." (Entrevistado C)
}

Essa fala salienta que a preocupação do aluno no processo está baseada em simplesmente ser aprovado nas tarefas e que as mesmas não chegam a determinar um real aprendizado, limitando o aluno a simplesmente cumprir tarefas.

\section{Considerações finais}

Diante do fato de a educação profissional apresentar contornos de educação tecnológica, é preciso ressaltar que esta modalidade educativa pode proporcionar um maior acesso ao cidadão no sentido de uma transformação social, mas se pode afirmar que não é o suficiente.

Estudos analisam como os percursos de formação e as trajetórias de vida interagem, evidenciam a relevância da experiência na construção de saberes e na aprendizagem de jovens e adultos e mostram que os tempos formadores são demasiadamente importantes para serem reduzidos aos das formações instituídas 
(Charlot, 1997; Pineau, 2004 e Silva, 2007). A necessidade de considerar "a autoria dos sujeitos da/em formação, dimensão fundamental para o seu (auto) reconhecimento social e para a (re) construção de identidades" explicita novos desafios para os modos de pensar e de organizar a formação (Silva, 2007, p. 1).

Como a análise se restringe a apenas um espaço educativo, dessa nova geração de espaços profissionais e tecnológicos, há que se sublinhar que as considerações finais, a título de conclusão, são bastante relativas e restritas.

Apesar disso, podem sugerir algumas indicações, visando a subsidiar gestores públicos no aprimoramento de políticas educacionais profissionais e tecnológicas.

Há o reconhecimento de que, no plano legal, existem diretrizes que apontam uma perspectiva de incentivo ao oferecimento da educação profissional e tecnológica para os cidadãos como um processo coletivo, organizado, de busca prática de transformação das relações sociais desumanizadoras.

Porém, por sua complexidade, a transposição do discurso legal, para a práxis escolar ainda tende a um distanciamento.

Apesar de existir uma política na estruturação física desses espaços educativos, no que concerne a recursos e equipamentos, ao se considerar a atuação pedagógica, no sentido de planejamento coletivo de projetos, discussão do currículo, análise de práticas de relevância, as ações políticas ocorrem com menos intensidade do que se deveria.

Como indicativos de ações, pode ser apontada, como primeira ação, a estratégia constante de formação continuada para que todos os atores, especialmente o pessoal técnico e docente, se conscientizem com relação à importância dos conceitos: competências, habilidades, currículo; no sentido de sinalizá-los sobre o real sentido do que ensinam, melhorando o planejamento e a seleção do currículo, inclusive contextualizando para os responsáveis do design instrucional das disciplinas cursadas, em EAD, nos Cursos de Qualificação Profissional.

A segunda seria o registro das ações realizadas no cotidiano para possibilitar melhoria no processo educativo através da açãorreflexãoação ${ }^{1}$, possibilitando a renovação e trazendo assim o saber-fluxo que Lévy aponta em seus estudos.

A terceira seria a integração maior das disciplinas dos cursos através do trabalho por projetos, ressaltando que, muitas vezes, a equipe pedagógica, no anseio de cumprir metas e calendários, descarta os momentos de reunião e planejamento entre os professores, tratando-os como meros executores e cumpridores de tarefas. Fica claro que, quando a execução de atividades é fruto do planejamento coletivo, a 
possibilidade do sucesso e engajamento de todos torna-se bem maior. O trabalho por projetos propicia o desenvolvimento de capacidades para resolver problemas novos, comunicar ideias, tomar decisões, ter iniciativa, ser criativo e ter autonomia intelectual, num contexto de respeito às regras de convivência democrática.

A quarta seria a manutenção dos projetos de integração e contextualização entre os diferentes níveis de cursos profissionalizantes, pois ressalta os princípios da ética e respeito entre as diferentes categorias existentes para a mesma área de trabalho e reconhecimento das dificuldades implícitas em cada função.

Como quinta ação, recomenda-se que, no processo de contratação do quadro do magistério e quadro de instrutores técnicos, tenham tratamento equânime em relação às suas funções. Além disso, devem ser alvo de programas específicos voltados ao desenvolvimento de competências docentes, inclusive com relação às NICTs para que componham harmonicamente a equipe com os demais professores que têm licenciatura nos diferentes componentes disciplinares de educação geral e, portanto, já possuem tais competências.

Fica a sugestão de capacitação da equipe técnico-pedagógica para gerir melhor o processo no que concerne a planejamento, currículo, implementação e avaliação ligados à EAD.

Com relação ao aspecto de possibilitar autonomia e autoaprendizagem, através da EAD, traçando-se um paralelo entre entrevistados e a observação participante, revelou-se que houve, sim, um "despertar" para a possibilidade de aprendizagem autônoma para os alunos desses cursos, mas que diante da ausência de pré-requisitos de conhecimento básico, ainda há muito que se caminhar na educação tecnológica nesse sentido, para que não se crie um "bloqueio" para esses alunos ao usar as NICTs.

Como finalização, destaca-se que este trabalho, com as considerações apresentadas, tem pertinência circunscrita ao caso observado, podendo, entretanto, estimular diferentes olhares para o relatado e propiciar conclusões que o complementem, confirmem ou contraditem, visando contribuir para a implementação de políticas de aprimoramento da educação profissional e tecnológica.

\section{Nota}

1 "açãorreflexãoação" é um termo mencionado em Pimenta, Selma Garrido. A construção da didática no GT Didática: análise de seus referenciais. São Paulo, SP: Revista Brasileira de Educação, v.18, no 52, 2013. 


\section{Referências bibliográficas}

Belloni, M.L. (2006). Educação a Distância (4 ed., p.116). Campinas: Autores Associados.

Brasil. MEC - SENTEC. Proeja - Programa Nacional de Integração da Educação Profissional à Educação Básica na Modalidade de Educação de Jovens e AdultosEducação Profissional Técnica de Nível Médio / Ensino Médio. Documento Base. $2^{a}$ ed., Brasília: MEC, agosto de 2007b. Acesso em 14/11/2013, disponível em http://portal.mec.gov.br/setec/arquivos/pdf2/proeja medio.pdf

Candau, V. M. F. (1984). A Didática em questão (2 ed., p.128). Petrópolis: Vozes.

Castells, M. (2007). A Sociedade em rede (Vol.1., p. 698). São Paulo: Paz e Terra.

Castro, M. R.; Ferreira, G.; Gonzalez, W. (2013). Metodologia da Pesquisa em Educação (1 ed., p.179). Nova Iguaçu: Marsupial.

Charlot, Bernard. (1997). Du rapport au savoir. Éléments pour une théorie (112 páginas). Paris: Anthropos.

Figueiredo, A.M.; Souza, S.R.G. (2011). Como elaborar Projetos, Monografias, Dissertações e Teses. Rio de Janeiro: Lumen Juris.

Flick, Uwe. (2009). Introdução à pesquisa qualitativa (3 ed., p.406). Porto Alegre: Artmed.

Freire, P. (2006). Pedagogia da autonomia (p.150). Rio de Janeiro: Paz e Terra.

Freire, P. (2005). Pedagogia do oprimido (43 ed., p.256). Rio de Janeiro: Paz e Terra.

Frigotto, G. (1998). A educação e formação técnico-profissional frente à globalização excludente e o desemprego estrutural. In: SILVA, L. H. da (Eds.). A escola cidadã no contexto da globalização (pp 218-239). Petrópolis-RJ: Editora Vozes.

Lévy, P. (1999). Cibercultura (2 ed., p.264). São Paulo: Editora 34.

Linard, Monique. (1996). Dês Machines et dês Hommes. Paris: L'Harmattan.

Martín-Gordillo, M.; Osorio, C. Educar para participar en ciencia y tecnología. Un proyecto para la difusión de la cultura científica. In: Revista Iberoamericana de Educación, 2003. Acesso em 15/11/2013, disponível em http://www.rieoei.org/rie32a08.pdf

Mazzotti, Alda Judith Alves. Artigo: "Usos e abusos dos estudos de caso". Cadernos de Pesquisa, v. 36, n. 129, set./dez., Rio de Janeiro, 2006. Acesso em 15/11/2013, disponível em: http://www.scielo.br/pdf/cp/v36n129/a0736129 
Pineau, G. (2004). Temporalidades na formação: rumo a novos sincronizadores (234 páginas). São Paulo: Triom.

Silva, A. M. C. (2007). Formação: espaço-tempo de mediação na construção de identidade(s). Coimbra: ARIADNE Editora. Acesso em 15/11/2013, disponível em http://www.fpce.up.pt/trabalhodocenteformacao/assets/TrabalhoDocenteEForma cao Vol I.pdf 